jaw; the bite was only large enough to admit the tip of the little finger-a quarter of an inch. The movements of the jaw were performed largely by the muscles on the left side owing to interference with the action of the right temporal muscle, and the jaw got pushed over towards the right side. On July 29th, under chloroform, the sinus was opened up and an incision made upwards in front of the tragus. The parts behind the zygoma right down to the sigmoid fossa and backwards over the capsule of the temporomaxillary joint were thoroughly explored and scraped with a small Volkmann's spoon, yet nothing beyond granulation tissue was found. The wound was again packed and dressed at intervals of a day or two; still the sinus remained.

The patient was very keen for another operation, but as the difficulty in opening and closing the jaw had somewhat diminished, and knowing that foreign bodies in the human organism are, like the proverbial needle in a haystack, hard to find, I was in no hurry, and resolved to wait, and simply had the wound dressed. On Oct. 2nd, under chloroform, another opening was made by a horizontal incision and a director introduced towards the external angular process of the frontal. The director was pushed backwards to the outer wall of the orbit and greater wing of the sphenoid. At a depth of $1 \frac{1}{2}$ inches a hard substance was felt and removed in six pieces; these when put together measured a linear inch and consisted of blackened wood similar to the pieces removed from the cheek, but in the size and shape of a charred lucifer match. The wound was packed with gauze and gradually healed in ten days. The swelling rapidly disappeared, and the patient could open his mouth an inch. When seen on Dec. 27 th his bite was normal -i.e., $1 \frac{1}{2}$ inches. I have seen him frequently since, and he is perfectly well.

Liverpool.

\section{A CASE OF INTUSSUSCEPTION TREATED BY ENTERECTOMY.}

BY E. G. GAUNTLETT, M.B., B.S. LOND. F.R.C.S. ENG.

SURGEON TO OUT-PATIENTS, PADDINGTON GREEN CHLLDREN'S HOSPITAI; SENYOR SURGICAL REGISTRAR AND TUTOR, KING'S COLLFGE HOSPITAI.

A Boy, aged 10 months, was admitted to Paddington Green Children's Hospital on March 17th, 1913, with a history of screaming attacks, associated with drawing up of the legs, which had commenced 36 hours previously. The child had vomited several times since the onset, and had passed a motion composed almost entirely of blood 24 hours previous to admission, since when nothing had been passed by the rectum. The child had been previously well, and was still being fed on the breast. On admission the temperature was $99^{\circ} \mathrm{F}$., pulse 130, and respirations 32 . The child looked well nourished, but pale and ill; be slept at intervals, but frequently awoke screaming. The abdomen was not distended and moved with respiration; when palpated the child screamed and contracted the abdominal muscles. On rectal examination nothing abnormal could be felt, but on withdrawing the finger a motion was passed which contained no obvious blood. On examination under an anæsthetic a sausage-shaped tumour was felt lying obliquely under the right costal margin,
The abdomen was thereupon opened through the right rectus muscle and an ileo-colic intussuscep tion found, which extended for about 6 inches from the region of the ileo-cæcal valve. Ar attempt was made to reduce this in the usual way but it was found that the last $2 \frac{1}{2}$ inches could not be reduced by squeezing or gentle traction. The bowel at this point was dark in colour and friable, so that even moderate pressure caused the cæcum to commence to split. Resection of the irreducible portion was then carried out by the method suggested by Mr. A. E. Barker-namely, a resection of the intussuscepted portion through an incision in the ensheathing layer. ${ }^{1}$ Intestinal clamps were applied above and below the intus. susception and the entering and ensheathing layers sutured by interrupted Lembert stitches around its neck. A longitudinal incision was then made in the ensheathing layer and the intussuscepted portion pulled through it; this was cut off at its base, and the cut edges of the entering and returning layers were sutured with interrupted catgut stitches. The incision in the ensheathing layer was closed by Czerny-Lembert stitches. The abdomen was then closed in the usual way. The anæsthetic used was a mixture of chloroform and ether, administered by the open method.

Subsequently the child was given four ounces of saline, containing 1 minim of adrenalin, sub. cutaneously every four hours, for 24 hours, together with strychnine in minim doses hypodermically and 10 minims of brandy by the mouth every four hours. Later digitalin in minim doses was substituted for the strychnine. An enema was given on the second day with a good result, and the bowels acted three times naturally on the third day. The stitches were removed from the abdominal incision on the tenth day, healing being by first intention. The tempera ture rose after the operation, reaching $104^{\circ}$ on the third day, but returned to normal on the seventh day. The child went home well on March 31st.

I should like to acknowledge my thanks to Mr. J. Renfrew White for his after-care of the case, and to Dr. Hugh Paterson for very skilfully adminis. tering the anæsthetic.

Queen Anne-street, W.

\section{MULTIPLE MESENTERIC LIPOMATA CAUSING OBSTRUCTION.}

BY SPENCER MORT, M.D., CH.B. GLASG., F.R.C.S. EdIN., F.R.S.E.,

MEDICAL SUPERINTENDENT, EDMONTON INFIRMARY; LATE ASSISTAY TO REGIUS PROFESSOR OF SURGERY, AND M'CUNN RESEARCH SCHOLAR, UNIYERSITY OF GLASGOW.

LIPOMATOUs tumours are found in all tissues and organs where fat lobules are normally situated. The commoner positions of these tumours, as on the limbs or trunk, are well known, as also the fact that they may be present in localised or circumscribed masses, or less often as diffuse infiltrations. Apart also from actual tumour formation, it is common to find the storage of fat in the thoracic and abdominal walls, with an additional reserve in large masses in the subperitoneal and retroperitoneal tissues, and especially in the great omentum, producing great difficulties in locomotion, and mechanically impeding the physiological action ot the involved or adjacent organs.

I had occasion recently to operate on a patient suffering from intestinal obstruction, due directly 
to fatty change near the intestine, the mesentery of which was thickened and solidified by the addition of fat between its peritoneal layers, while the lumen was directly compressed from without by a rounded tumour of a similar nature.

The patient, aged 60 , was a corpulent old lady, the mother of eight children, whose life had been surgically uneventful till about one year before operation. She had a popliteal lipoma on the back of the right knee, and a fibroid mass on the left cheek, just in front of the ear. A gradual and progressive swelling of the abdomen was noted, at first without other symptoms than its growth, but later signs of interference by pressure on the viscera appeared. These were : a feeling of fulness after food, dyspepsia, sickness, vomiting, constipation, occasional sudden distension of the abdomen relieved usually by the passage of flatus in quantity, and rarely diarrhcea. Progressive development of this condition led to a state of chronic intestinal obstruction. Locally, there was an indefinite abdominal swelling, without the usual flabbiness associated with simple pendulous belly, and a provisional diagnosis of chronic obstruction of unknown cause was made. The age of the patient, the history, and a pallor of the face suggested carcinoma, but a complete vaginal and rectal examination did not confirm this, while there was also a lack of emaciation.

On Jan. 13th, 1914, I opened the abdomen in the middle line between the umbilicus and pubis, cutting through $2 \frac{1}{2}$ inches of oleaginous superficial fat. The great omentum was of the stiffness of cardboard, largely interladen with lobulated fat of $1 \frac{1}{2}$ inches in sectional thickness. The rigidity of the parts and the depth of the wound made a larger incision necessary, so the latter was extended above till the abdominal contents were freely exposed. The small intestines were attenuated and collapsed, their walls thrown into rugæ in many places. The mesentery was curiously packed with fat of a much denser nature than that found in the parietes, so that surgical manipulations were interfered with, and the free intestinal borders of the mesentery supported the intestine in an erect starched-like manner, holding it out in a fashion resembling an Elizabethan ruffe, which must have considerably lessened normal peristalsis. Many little tumours of the size of beans were studded in the mesentery, and one larger tumour, as big as a pigeon's egg, situated 9 inches from the ileo-creal valve, pressed on the ileum, and seriously diminished its calibre. (Fig. 1.) This

FIG. 1.

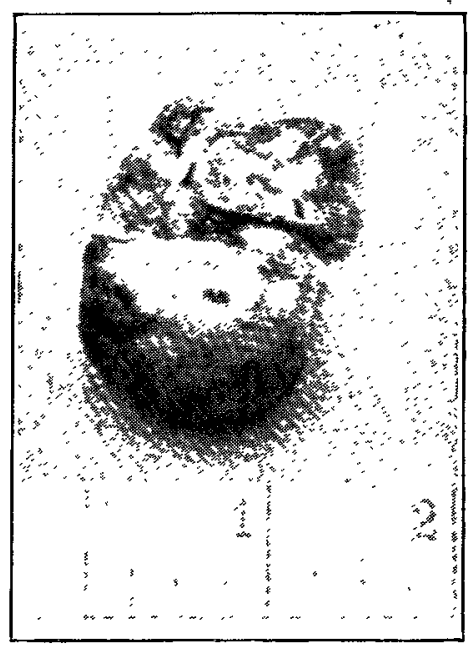

Lipoma pressing on the ileum, causing obstruction. Photograph of excised tumour with inch scale for comparison of size.

was easily shelled out after incising its peritoneal case, and the intestine thereupon resumed its natural size. The other abdominal organs were turned out by evisceration, and the fatty tags of the sigmoid and descending colon were found to be much enlarged, hanging on to the bowel like marbles, but evidently not interfering with the passage of the contents. The ascending colon was hitched up by a small perivisceral veil attached to the omentum, possibly of a congenital nature. There were no other lesions. There were thus two effects limiting due passage of the intestinal

contents, both depending on the abnormal development of fat-namely, a resistant mesenteric attachment of the small intestine of a diffuse nature, and a localised obstruction due to a circumscribed hypertrophy. (Fig. 2.)

After saline lavage of the peritioneum the abdominal wall was closed by sutures in layers, reinforced by two large relazation stitches of thick silk, as the contained viscera were rather tightly packed. Recovery was splendid. The symptoms of obstruction abated with the removal of the tumour, the more obvious impediment to free transit of intestinal material. An enema was given on the third day with good result, and repeated every second day for a week.

FIG. 2.

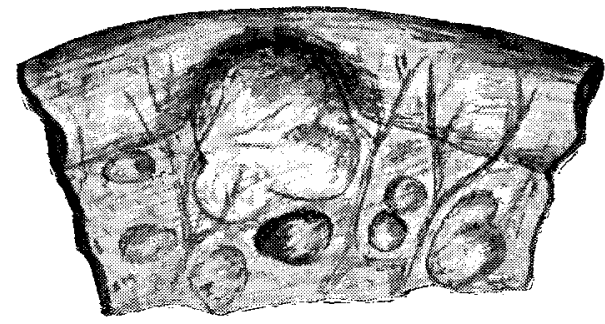

Diagram of obstruction of ileum by tumour.

Five days after operation cascara extract was given, and the nurse in charge reported that it was followed by a good natural motion, contrasting with the condition before operation when four or five repeated doses of the same drug were required to produce any purgative action. The wound was looked at after ten days and a sound linear scar, 7 inches in length, was seen. Recognising the diffusely thickened condition of the mesentery and its effect in diminishing proper vermicular action, pituitrin (P.D. and Co.) in $\frac{1}{2}$ c.c. ampoules was prescribed, this acting favourably in minimising stasis.

With a view to diminishing the general adipose state I intend giving extract of thyroid gland, the effect to be checked by the rate of the pulse, the weight, and the intestinal symptoms. This may lessen the diffuse fatty hypertrophy of the mesentery. I do not know what effect it has on definite circumscribed lipomata, but will note later if there is any apparent benefit, taking the external popliteal lipoma as a visible experimental control. Probably massage of the abdomen with a heavy ball (cannon-ball exercise) will be resorted to in order to diminish the fat, as well as to act mechanically on the muscular wall of the intestines.

I am unable to find a recorded case of a similar nature in the literature. Bland-Sutton ${ }^{1}$ describes the ordinary varieties of lipoma, and among special forms mentions tags of subperitoneal fat descending through the inguinal or femoral rings, fatty hernia of the linea alba at the umbilicus, lipoma of the mesometrium (cases noted by Treves ${ }^{2}$ and Parona ${ }^{3}$ ), over-development of the appendices epiploicæ, and subserous intestinal lipoma. The last-named variety is indeed very rare, but presents the most resemblance to the condition in my case.

Stabb, ${ }^{4}$ Lawford Knaggs, ${ }^{5}$ Langemak, ${ }^{6}$ Hahn, ${ }^{7}$ and Hiller ${ }^{8}$ have collected a limited number of cases of subserous lipoma, most of which were noted as causing intussusception, none of them leading directly to intestinal obstruction, while Nothnagel, and Mikulicz and Kausch ${ }^{10}$ merely refer to the condition as having been seen. A case of obstruction from a like tumour of the great intestine is reported by Bland-Sutton, ${ }^{11}$ a lipoma of the ascending colon situated 2 inches from the ileo-cæcal valve. Therefore, it appears that the present case is unique in being the only one in which a mesen. teric lipoma of the small intestine has caused danger to life by pressing on, and obstructing, the ileum. 
In the diagnosis of this condition laparotomy is the only sure means of clearing up doubt, though some other evidences may be considered in a suspected case. There will be no local signs of a carcinomatous nature on abdominal palpation or on rectal or raginal examination, no glandular or metastatic inrolrement, and no emaciation, but rather obesity, unless chronic stasis causes autointoxication or starvation. The onset will be very slow, for lipoma as a rule is one of the most tardy of neoplasms in dereloping, so the obstructive phenomena with periods of acute distress may be delayed and gradual. The age of development of this condition is indefinite, though it is not usual till middle life is reached.

Bibliography.-1. Bland-Sutton : Tumours, Innocent and Malignant, London. 2. Treves : Transactions of the Clinical Society of London, 1893 . Parona : Annali di Ostetricia, Milano, 1891. 4. Stabb : St. Thomas Hospital Reports, 1894. 5. Lawford Knaggs: THe LATCET, June 16th, 1900 , p. 1726, 6. Langemak: Beiträge zur Klinischen Chirurgie, 1900. . Habn: Minchener Medizinische Wochenschrift, 1900. 8. Hiller Beiträge zur Klinischen Chirurgie, 1899,9. Nothnagel: Diseases of Intestine and Peritonemm, 1904. 10. Mikulicz and Kausch : Bergmann's System of Surgery, 1904. 11. Bland-Sutton: The LiNCE'T, MaJ 19th, 1900 , p. 1437.

Upper Edmonton, N.

\section{attedical Socretties.}

\section{ROYAL SOCIETY OF MEDICINE.}

\section{SECTION FOR THE STUDY OF DISEASE IN CHILDREN.}

\section{Exhibition of Cases and Specimens.}

A MEETING of this section was held on Jan. 23rd, Dr. LeONARD GUTHRIE, the President, being in the chair. The following cases and specimens were shown :-

Dr. T. R. WhiphAM : A case of Kala-azar in a boy aged 5 years. His father contracted kala-azar in Calcutta a year ago and died recently from that disease. In March, 1913, when in Calcutta, the boy was taken ill with fever and loss of appetite. The motions at that time were white but otherwise normal. The abdomen was enlarged when he arrived in England in June, since when he had lost weight and the size of the abdomen had increased. The child was wasted, especially in the limbs and chest; the cervical, axillary, and inguinal glands were enlarged. The abdomen measured $24 \frac{1}{2}$ inches in circumference ; the liver extended 3 inches below the costal margin; the spleen was enormous, extending to the middle line and filling the left iliac fossa. Blood count: Red cells, 3,220,000 per c.mm.; white cells. 2200 ; polymorphonuclears, 46 per cent.; lymphocytes, 38 per cent. ; large mononuclears, 12 per cent. ; transitionals, 4 per cent ; hæmoglobin, 66 per cent. The coagulation time was diminished, being 12 minutes. Leishman-Donovan bodies were present in blood obtained by puncture of the liver.

Dr. WHIPHA M also showed a case of Athethoid Movements in a girl aged $4 \frac{1}{2}$ years. The movements, which were present in either hand, consisted of alternate pronation and supination, which became more marked when objects were grasped. The condition was probably due to injury at the time of birth.

Dr. F. LAxGMEAD showed a case of Malaria in a girl aged $3 \frac{1}{4}$ years. The disease, which commenced in September, 1913, was typical and accompanied by rigors. The mother had malaria while the child was being breast fed. The spleen extended downwards for four finger-breadths below the costal margin, and the liver was also slightly enlarged. Examination of the blood showed benign tertiary parasites in fair numbers, large intracorpuscular forms being seen.

Dr. ERrC Pritchard showed a case of Abnormal Cysts on the Shoulders in a baby 6 weeks old. The two cystic swellings were noticed immediately after birth. The presentatic $n$ is said to have been that of a shoulder (left). The swellings appear to be of the nature of abnormal and persistent capita succedanea.
Dr. J. W. CARR showed a case of (?) Polio-encephalitis. The patient, a boy aged 7 years, had an attack of diarrhce with severe headache and pains in the limbs in October. 1913. He became unable to stand or speak and also appeared to be blind. On admission in December he could not stand alone and could see only imperfectly, and there was a considerable degree of mental deficiency. The optic discs showed evidence of a subsiding neuritis. After five weeks be began to improve as regards mental condition, sight, and movement, though he still had an ataxic gait. Wassermanns reaction was negative.

Dr. F. G. Crookshank showed a case of Deficiency of Endocrinic Glandular Secretion. The patient, a boy agel 32 months, did not speak and was apathetic and flaccid. Some of the features were suggestive of Mongolism. It was thought that the child had in addition to some degree of Mongolism some pituitary deficiency.

Dr. H. D. Rolleston and Mr. E. J. Boyd showed a case of Lymphatic Leukæmia under treatment by Benzole. A boy, aged $6 \frac{1}{2}$ years, developed enlargement of the cervical glands after measles and pneumonia. Subsequently the axillary, inguinal, and submaxillary glands also enlarged and the spleen was palpable. In December the leucocytes were 60,000 ; large lymphocytes, 54 per cent.; small, 16.5 per cent. ; and polymorphonuclears, 25 per cent. He was treated with benzole, at first two minims, and later three minims, three times a day. On Jan. 13th the leucocytes were 16,000 ; large lymphocytes, 41.5 per cent.; small, 46 per cent. ; and polymorphonuclears, 10 per cent.

Mr. Philip TurNer showed a case of a Dental Cyst following Fracture of an Incisor Tooth in a boy aged 12 years. The right central incisor was fractured as the result of a fall two years ago. Swelling of the jaw was noticed three months ago. There was now bulging forward of the facial aspect of the superior maxilla, depression of the palate on the right side, and widening of the alveolar process. A radiogram showed that the pulp cavity of the fractured tooth was exposed, and that the open apex led directly to the cyst.

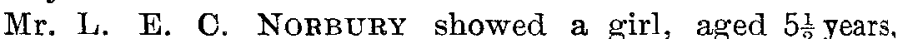
with Deformity of the Spine of (?) congenital origin. There was a prominence of the last dorsal and the first lumbar spinous processes. There was slight mid-dorsal lateral curvature with convexity to the left. There was no pain or rigidity. $\mathrm{X}$ ray examination showed a wedge-shaped con. dition of the first and secoad lumbar vertebre. The von Pirquet reaction was slightly positive.

Dr. PRITCHaRD showed a specimen of Double Hydro. Ureter (congenital) in an infant, aged 7 months, who was admitted for diarrhoa and vomiting. The bladder was not distended, but two cystic swellings could be felt internal to the anterior superior iliac spines. The obstruction appeared to have been due to valve-like pressure of the dilated ureters, the primary dilatation being probably due to congenital atresia of the ureteral orifices. The renal pelres were greatly enlarged.

Dr. J. Porter PARKinson showed specimens from an unusual case of Jaundice which he considered to have been acute yellow atrophy of prolonged duration. The illness commenced with a rigor. Three weeks later jaundice appeared. The liver was then enlarged but subsequently diminished until death. No leucin or tyrosin was detected in the urine.

The President and Dr. G. A Sutherland made a communication on two cases of Transitory Diabetes Insipidus. The first case was a boy, aged $2 \frac{1}{2}$ years, in whom the disease lasted about six weeks. He took 12 pints of water a day, and the urine which contained no albumin or sugar was of specitic gravity 1004 . There was some diarrhoea and the motions were of a peculiar bluish-grey colour. In the second case, a boy aged two years, the duration was about five weeks. The main symptoms were thirst, drowsiness, and polyuria. There $\mathrm{was}$ diarrhoea and the motions were loose, putty-coloured, and offensive. The liver and spleen were enlarged. A possible explanation is that the intestinal derangement set up toxæmia, which acting on the kidneys prevented the output of waste products. Another explanation is that the symptoms were due to toxæmic affection of the vaso-motor centres and sympathetic system, or perhaps of the pituitary body. 